Check for updates

Cite this: Mater. Adv., 2020, 1,804

Received 7th May 2020, Accepted 29th May 2020

DOI: $10.1039 / \mathrm{d} 0 \mathrm{ma} 00289 \mathrm{e}$

rsc.li/materials-advances

\section{Hybrid poly(allylamine hydrochloride)-graphene oxide microcapsules: preparation, characterization and application in textiles with controlled release behaviort}

\author{
Zhiqi Zhao, ${ }^{\mathrm{ab}}$ Qiujin Li, (D)*ab Jixian Gong, ${ }^{* a b}$ Zheng Li ${ }^{\mathrm{ab}}$ and Jianfei Zhang ${ }^{\mathrm{abc}}$
}

\begin{abstract}
Permeable microcapsules are suitable forming blocks for functional materials based on controlled release. This study reports the design of a stimuli-responsive fabric coated with a type of hybrid microcapsules prepared via a layer-by-layer (LBL) approach. The resulted fabric can be used as a healthy care material. The functional microcapsules comprise polyelectrolytes poly(allylamine hydrochloride) (PAH) and graphene oxide (GO). The self-assembly of these oppositely charged surrounding components generated a hollow space to load functional molecules such as dyes, labels and drugs via a responsive trigger. The polyelectrolyte PAH ensured a robust structure and $\mathrm{pH}$ sensibility. GO sheets provided near-infrared (NIR) laser-induced release through photothermal effects. These hybrid microcapsules (PAH/GO) ${ }_{n} \mathrm{PAH}$ can then be used to load Atractylodes, a traditional Chinese herb, and then adhere to cotton fabrics to develop functional textiles. The encapsulated Atractylodes can then be released from the (PAH/GO) ${ }_{n} \mathrm{PAH}$-coated cotton fabric. During the subsequent period of the entire process, the release rate was significantly accelerated by NIR irradiation. After washing 20-30 times, microcapsules were coated on cotton fibers. Using this technique, functional textiles for controlled release by external stimulation coupled with other synergetic effects could be obtained. Note that $(\mathrm{PAH} / \mathrm{GO})_{n} \mathrm{PAH}$ microcapsules can provide sustained drug release in simulated sweat and control the release rate through NIR irradiation, which shows its potential as an external skin drug delivery system.
\end{abstract}

\section{Introduction}

Microencapsulation has already been considered as an efficient technique for generating materials with a long-lasting behavior. Microcapsules usually exhibit optical or $\mathrm{pH}$ response due to their structural and compositional properties. ${ }^{1-4}$ In recent years, stimuli-responsive microcapsules have been rapidly developed. Sukhorukov et al. reported that UV lightresponsive microcapsules can achieve the remote-controlled release of embedded materials only by external UV stimulation without direct contact or interaction. In addition to singleresponsive microcapsules, multi-responsive microcapsules have drawn considerable attention. ${ }^{5}$ Sukhorukov et al. designed

\footnotetext{
${ }^{a}$ School of Textile Science and Engineering, Tiangong University, Tianjin 300387, China. E-mail: vicmaldini@126.com, gongixian@126.com; Tel:+86-18622272697, +86-18920787809

${ }^{b}$ Key Laboratory of Advanced Textile Composites, Ministry of Education, Tiangong University, Tianjin 300387, China

${ }^{c}$ Collaborative Innovation Center for Eco-Textiles of Shandong Province, Qingdao 266071, Shandong, China

† Electronic supplementary information (ESI) available. See DOI: 10.1039/ d0ma00289e
}

a new type of inorganic/organic hybrid capsule with unique physicochemical properties for multi-conditional responsiveness to physical (ultraviolet, ultrasonic) and chemical (enzymatic treatment) stimuli. Different stimulations could be used for the controlled release of numerous substances. ${ }^{6}$ As reported by Willner et al., a method for constructing stimuli-responsive DNA-acrylamide-based hydrogel microcapsules was produced. Preliminary studies represented that these ATP- or $\mathrm{pH}$ responsive microcapsule-encapsulated doxorubicin expressed a selective cytotoxic effect on MDA-MB-231 cancer cells. ${ }^{7}$ In our study, we used superparamagnetic iron oxide (SPIO) and PAH to form magnetic microcapsules with low magnetization used in MRI contrast tracking, hyperthermia and drug delivery. ${ }^{8}$

Usually, microcapsules work as a carrier for active ingredients with releasing behavior under environmental stimulation, which can be considered as a blocking part of a stimuliresponsive material. Stimuli-responsive textile fabrics have emerged as an important aspect in functional materials, thus yielding a myriad of applications such as textile sensors, selfrepairing materials and drug delivery materials. ${ }^{9-13}$ Different stimuli factors can be used to drive responsive textiles, including temperature, magnetic field, $\mathrm{pH}$ and electric field. ${ }^{14,15}$ 
Microcapsules sealing various substances within small vectors can be easily combined with textile fibers, which have been studied in several areas in terms of controlled release and delivery properties. ${ }^{16,17}$ The combination of microcapsules with fabrics is a feasible method to introduce functional chemicals into textiles. ${ }^{18-20}$ By changing the surrounding environment (e.g. light, $\mathrm{pH}$ or temperature), the functional chemicals would release the carrier that bonded with textiles. Graphene oxide (GO) is a superior carbon nanomaterial that acted as the blocking part of a carrier for controlled release due to its responsiveness to near infrared (NIR) laser. Compared with other composite structures, hollow microcapsules of GO exhibit much higher loading amount because the advanced sheet-like structure of GO stabilizes the capsule shell, thus preventing the leakage of loaded substances. ${ }^{21-23}$ Therefore, functional composites based on graphene coupled with other materials such as polymers have been extensively developed. ${ }^{24,25}$ Besides, it is necessary to study the stimuli-responsive textile which combined with GO composites. Microcapsules with $\mathrm{pH}$ - and NIR-responsiveness can be applied on a pure cotton fabric by coating and can become suitable materials for direct contact with human skin because a weakly acidic solution in sweat can induce the release of chemicals out of microcapsules. ${ }^{26,27}$ Simultaneously, NIR radiation can be considered as the external stimulation to trigger the remotely controlled release behavior of certain microcapsules coated on textiles. ${ }^{28,29}$

Atractylodes, beneficial for invigorating the spleen and eliminating dampness, is extensively distributed in China. As a type of Chinese traditional medicine, Atractylodes has been extensively used for treating rheumatic diseases, digestive disorders, hepatic protection and influenza. ${ }^{30}$ The major ingredient effectively works for releasing pain from arthritis. ${ }^{31}$ Besides, it is reported that Atractylodes has pharmaceutical activities such as anticancer activities, activities on nervous, activities on gastrointestinal systems and activities on cardiovascular system. ${ }^{32}$
Furthermore, Atractylodes is a suitable ingredient which can be loaded into microcapsules for controlled release. This study presents a type of self-assembled hybrid microcapsules comprising poly(allylamine hydrochloride) (PAH) and GO nanosheets using a layer-by-layer technique. Under NIR irradiation, these hybrid microcapsules can be easily coated on cotton fabrics to manufacture functional textiles with a controlled releasing behavior. The GO nanosheet is considered as a functional layer between polyelectrolytes layers due to its responsiveness to NIR. This microcapsule-coated fabric can be envisioned as a functional textile for healthy care treatment. Importantly, these microcapsule-coated cotton fabrics can be used as a type of responsive NIR-triggered textile with the controlled release of Atractylodes for treating both rheumatism and arthritis. Combining photothermal effect and remotely controlled release by an external stimuli factor, i.e., NIR laser, this Atractylodes-microcapsule-coated fabric generated an innovative functional textile for health care treatment.

\section{Experimental}

\subsection{Materials}

Poly(allylamine hydrochloride) (PAH) and poly(styrene sulfonic acid) sodium salt (PSS $M_{\mathrm{w}} \approx 70 \mathrm{kDa}$ ) were purchased from Alfa Aesar (Tianjin) Co., Ltd. Graphene oxide (GO) was purchased from Nanjing Pioneer Nanomaterials Co. Ltd. Atractylodes was purchased as a herbal medicine from Tianjin Yongchun Pharmacy and ground into a powder before use. An epoxyethane quaternary ammonium salt was used as a crosslinker. The other reagents were of analytical grade. Standard 100\% cotton fabric (weight $=106.6 \mathrm{~g} \mathrm{~m}^{-2}$; warp $=133$ yarns per inch; weft $=72$ yarns per inch; thickness $=0.21 \mathrm{~mm}$ ) was purchased from Tianyi printing and dyeing company in Tianjin, China. A hemocytometer was purchased from Changde BKMAM Biotechnology Co., Ltd.

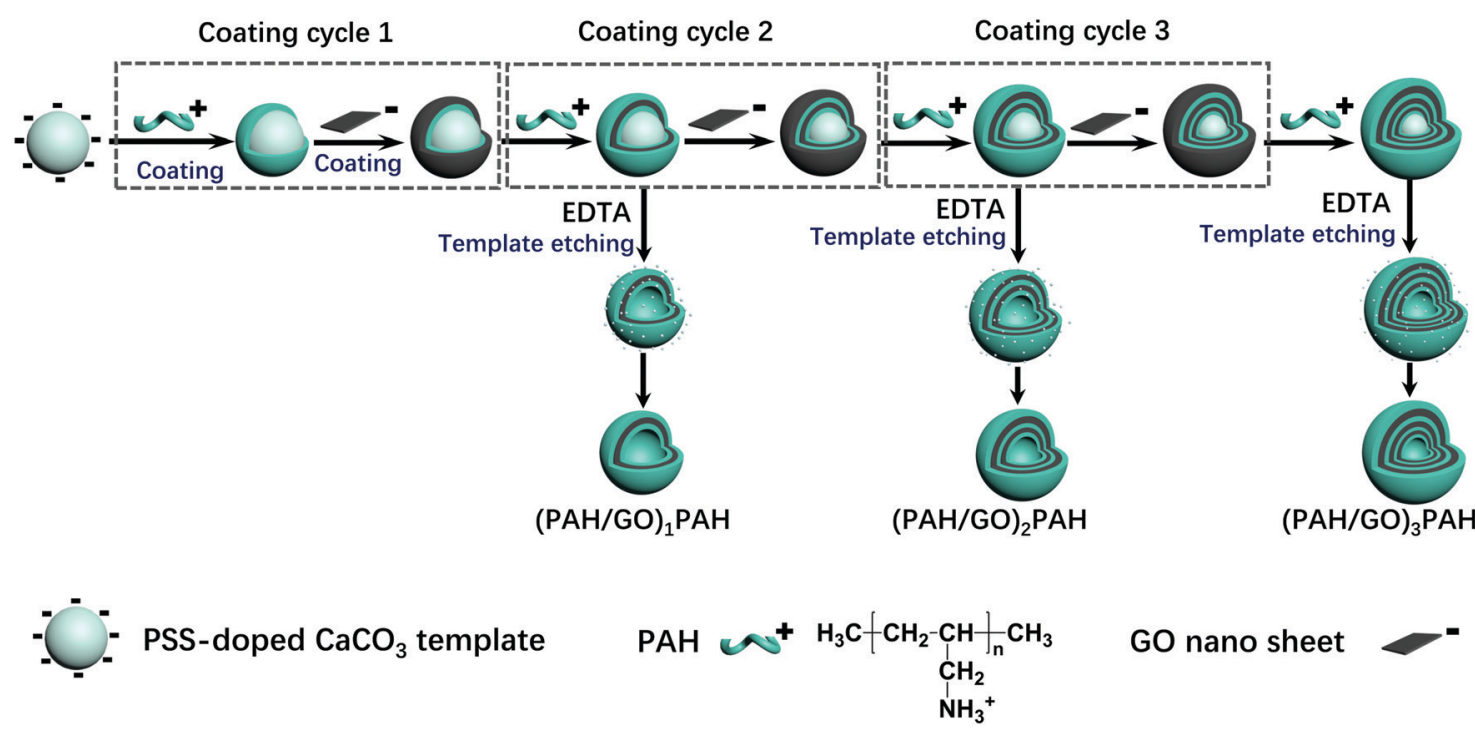

Scheme 1 Schematic of $(\mathrm{PAH} / \mathrm{GO})_{n} \mathrm{PAH}$ microcapsules prepared via a layer-by-layer assembly. 


\subsection{Preparation of graphene oxide nanosheets}

Graphene oxide (GO) was dispersed in distilled water $\left(1.0 \mathrm{mg} \mathrm{mL}^{-1}\right)$ under ultrasonication for 10-15 min for three times, followed by the addition of $500 \mathrm{mg} \mathrm{NaOH}$. The mixture was maintained at $45^{\circ} \mathrm{C}$ for $4 \mathrm{~h}$ under stirring. Then, the solution was sonicated using an ultrasonic homogenizer system (JY92-IIN, Ningbo Scientz Biotechnology Co. Ltd) for $2 \mathrm{~h}$. The parameters were set as $70 \%$ of output, $2 \mathrm{~s}$ of "operation on" and $4 \mathrm{~s}$ of "operation off". Subsequently, the suspension was neutralized by dialysis (3500 Da) against deionized water for $48 \mathrm{~h}$ with frequent water-related changes. Finally, the neutralized GO suspension was sonicated for $2 \mathrm{~h}$, followed by centrifugation, and the resultant nano GO solution was stored at $4{ }^{\circ} \mathrm{C}$ for further use.

\subsection{Preparation of $(\mathrm{PAH} / \mathrm{GO})_{n} \mathrm{PAH}$ microcapsules}

$\mathrm{Ca}\left(\mathrm{NO}_{3}\right)_{2} \cdot 4 \mathrm{H}_{2} \mathrm{O}$ solution $(100 \mathrm{~mL}, 0.025 \mathrm{M})$ comprising $200 \mathrm{mg}$ of PSS $\left(M_{\mathrm{w}} \approx 70 \mathrm{kDa}\right)$ was quickly poured into $\mathrm{Na}_{2} \mathrm{CO}_{3}(100 \mathrm{~mL}$, $0.025 \mathrm{M}$ ) under stirring. After $15-30 \mathrm{~min}$, the precipitated $\mathrm{CaCO}_{3}$ particles were washed and collected. $\mathrm{CaCO}_{3}$ templates were then dispersed into the PAH solution $\left(10 \mathrm{~mL}, 1.0 \mathrm{mg} \mathrm{mL}^{-1}\right.$, and $0.5 \mathrm{M}$ $\mathrm{NaCl})$ for $15 \mathrm{~min}$ under continuous stirring (120 rpm). The resultant particles were washed three times and collected using centrifugation (8000 rpm for $1 \mathrm{~min}$ ). Then, the coated particles were incubated in GO solution $\left(10 \mathrm{~mL}, 0.1 \mathrm{mg} \mathrm{mL}^{-1}\right)$ using the same procedure. The multilayer structure was formed by the alternative assembly of corresponding materials, and the hollow hybrid microcapsules were obtained by etching $\mathrm{CaCO}_{3}$ templates using EDTA (30 mL, 0.1 M, pH 7.0). The process is shown in Scheme 1.

\subsection{Characterization of $(\mathrm{PAH} / \mathrm{GO})_{n} \mathrm{PAH}$ microcapsules}

The TEM images of $(\mathrm{PAH} / \mathrm{GO})_{n} \mathrm{PAH}$ microcapsules samples were recorded using a transmission electron microscope (TEM) (Hitachi H7650, HITACHI). The samples for the TEM analysis were prepared by dropping a diluted microcapsule solution onto the standard 400-mesh TEM carbon-coated $\mathrm{Cu}$ grid, and then the solvent was evaporated at room temperature before imaging. The morphology of $(\mathrm{PAH} / \mathrm{GO})_{n} \mathrm{PAH}$ microcapsules was characterized by a scanning electron microscope (SEM) (Hitachi S4800, HITACHI) under an accelerating voltage of $20 \mathrm{kV}$. Moreover, the particle size of PSSdoped $\mathrm{CaCO}_{3}$ particles was measured using a laser diffraction analyzer (LA-300, HORIBA). Raman spectra were recorded using a Raman microscope with a Renishaw CCD detector (British Renishaw Company). Fourier transform infrared (FTIR) spectroscopy was performed on a Nicolet is 50 (Thermofisher Technology) spectrometer to obtain the vibration modes of functional groups within $400-4000 \mathrm{~cm}^{-1}$.

\subsection{NIR-triggered RhB release from $(\mathrm{PAH} / \mathrm{GO})_{n} \mathrm{PAH}$ microcapsules}

$(\mathrm{PAH} / \mathrm{GO})_{n} \mathrm{PAH}$ microcapsules $\left(2 \mathrm{mg} \mathrm{mL}{ }^{-1}, 1.0 \times 10^{8}\right)$ were then washed and centrifuged three times (7000 rpm $\min ^{-1}, 1 \mathrm{~min}$ ). Then, the washed microcapsules were incubated in a Rhodamine $\mathrm{B}(\mathrm{RhB})$ solution $\left(2 \mathrm{~mL}, 1 \mathrm{mg} \mathrm{mL}{ }^{-1}\right)$ at $25{ }^{\circ} \mathrm{C}$ for $24 \mathrm{~h}$. The resultant microcapsules were centrifuged and washed with $\mathrm{PBS}(\mathrm{pH} 7.4)$ to calculate the loading efficiency (eqn (1-1)). The release experiment of $(\mathrm{PAH} / \mathrm{GO})_{n} \mathrm{PAH}$ microcapsules was performed in two buffers (pH 5.8 and $\mathrm{pH} 7.4$ ), and the release with the intermittent treatment by NIR laser was tested. The NIR laser was purchased from Changchun New Industries Optoelectronics Technology Co., Ltd $(\mathrm{PAH} / \mathrm{GO})_{n} \mathrm{PAH}$ microcapsules, which were irradiated with a NIR laser of $808 \mathrm{~nm}$ at $0.5 \mathrm{~W} \mathrm{~cm}^{-2}$ for $1 \mathrm{~min}$. The release behavior was as follows: RhB-loaded microcapsules $\left(\sim 1.0 \times 10^{8}\right)$ were mixed with PBS (5 mL, pH 5.8 and 7.4) and $3 \mathrm{~mL}$ of supernatant was obtained at different time intervals for absorbance measurement ( $\lambda=554$ nm, UV-1200 spectrophotometer, Mapada Instrument Co., Ltd), and then the supernatant was poured back into the initial solution. Finally, the cumulative release was obtained (eqn (1-2)).

$$
\begin{gathered}
\text { Loading efficiency }(\%)=\frac{C_{0} V_{0}-C_{1} V_{1}}{C_{0} V_{0}} \times 100 \% \quad(1-1) \\
\text { Release rate }(\%)=\frac{C_{t} V_{t}}{C_{0} V_{0}-C_{1} V_{1}} \times 100 \%
\end{gathered}
$$

where $C_{0}\left(\mathrm{mg} \mathrm{mL}^{-1}\right)$ and $V_{0}(\mathrm{~mL})$ are the initial concentration and volume of the RhB solution; $C_{1}\left(\mathrm{mg} \mathrm{mL}^{-1}\right)$ and $V_{1}(\mathrm{~mL})$ are the concentration and volume of the RhB solution after the incubation of microcapsules; and $C_{t}\left(\mathrm{mg} \mathrm{mL} \mathrm{m}^{-1}\right)$ and $V_{t}(\mathrm{~mL})$ are the concentration and volume of the RhB solution at different time intervals
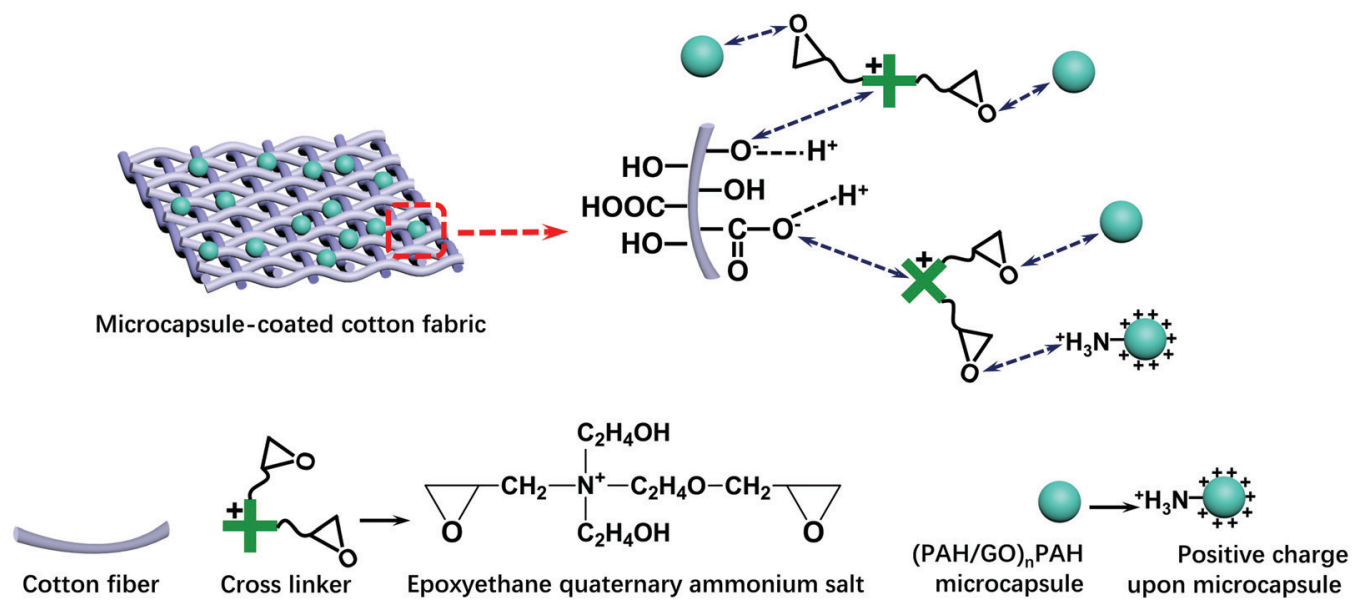

Scheme 2 Combination of (PAH/GO $)_{n} \mathrm{PAH}$ microcapsules with cotton fabric through an epoxyethane quaternary ammonium salt as cross linkers. 
during the release process. The concentration can be calculated through the absorbance value and calibration curve.

\subsection{NIR-triggered Atractylodes release from (PAH/GO) ${ }_{n} \mathrm{PAH}$ microcapsules}

For the release behavior of Atractylodes, the powder of Atractylodes was immersed in deionized water $\left(250 \mathrm{~mL}, 20 \mathrm{mg} \mathrm{mL}^{-1}\right)$ bind microcapsules with cotton fabrics. Scheme 2 shows the combination of $(\mathrm{PAH} / \mathrm{GO})_{n} \mathrm{PAH}$ microcapsules with cotton fabrics using a cross-linker. The morphologies of microcapsule-coated cotton fabrics were characterized, and the coating percentage of the microcapsule-coated fabrics was calculated as follows:

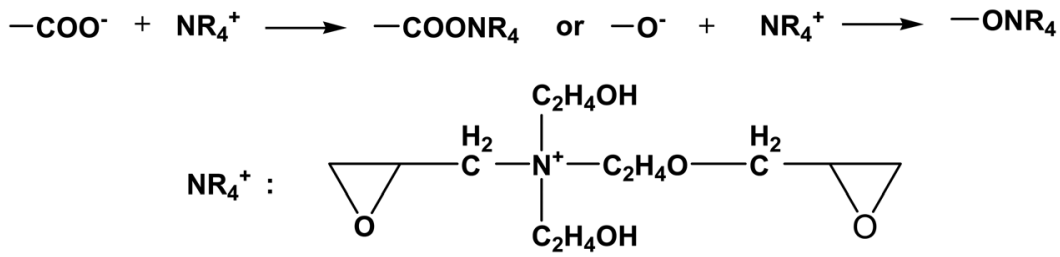

and boiled for $20 \mathrm{~min}$ to extract the primary component from Atractylodes. The resultant mixture was centrifuged $(10000 \mathrm{rpm}$, $10 \mathrm{~min}$ ) to collect the supernatant. Moreover, (PAH/GO) ${ }_{n} \mathrm{PAH}$ microcapsules were incubated into the above supernatant at $25{ }^{\circ} \mathrm{C}$ for $24 \mathrm{~h}$, and then the microcapsules were collected by washing and centrifugation. The release behavior of Atractylodes from $(\mathrm{PAH} / \mathrm{GO})_{n} \mathrm{PAH}$ was monitored using the same procedure for measuring $\mathrm{RhB}$ release.

\subsection{Coating (PAH/GO $)_{n}$ PAH microcapsules on cotton fabrics}

The cotton fabrics $(5 \mathrm{~cm} \times 5 \mathrm{~cm})$ were washed thrice with deionized water and immersed into $(\mathrm{PAH} / \mathrm{GO})_{n} \mathrm{PAH}$ microcapsule suspension $\left(1.0 \times 10^{8}, 10 \mathrm{~mL}\right)$ of different $\mathrm{pH}$,

$$
\text { Coating percentage }(\%)=\frac{N_{0}-N_{1}}{N_{0}} \times 100 \% \quad(1-3)
$$

where $N_{0}$ is the initial microcapsules number added into the system, and $N_{\mathrm{i}}$ is the microcapsules number in the system after coating on the cotton fabric. The number of microcapsules was calculated using hemocytometers.

The positively charged part $\mathrm{NR}_{4}{ }^{+}$of the cross linker was bonded with $-\mathrm{COO}^{-}(-\mathrm{COOH})$ or $-\mathrm{O}^{-}(-\mathrm{OH})$ groups of cotton fiber, and the reaction equations are as follows:

The ethylene oxide groups interacted with the $-\mathrm{NH}_{3}{ }^{+}$ group of the outermost layer $\mathrm{PAH}$ of the $(\mathrm{PAH} / \mathrm{GO})_{2} \mathrm{PAH}$

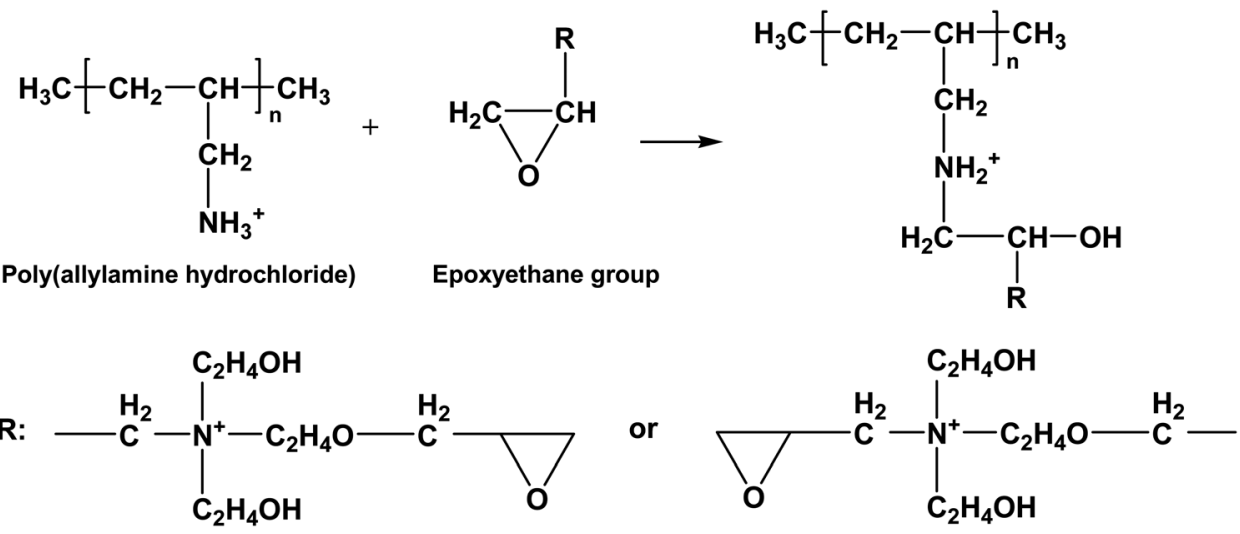

followed by shaking for $30 \mathrm{~min}(120 \mathrm{rpm})$. The morphology of the (PAH/GO) ${ }_{n} \mathrm{PAH}$ microcapsule-coated fabrics was characterized by SEM. An epoxyethane quaternary ammonium salt as the cross linker was added into the suspension to microcapsules. The following reaction (eqn (1-5)) is the formation of the secondary amine and hydroxyl group between epoxyethane and primary amine. ${ }^{33}$ The reaction equation is as follows:<smiles>[R]C(O)C[NH2+]CC(C)CC</smiles><smiles>[R]C1CO1</smiles><smiles>[R]C(O)C[NH+](CC([R])O)CC(C)CC</smiles> 

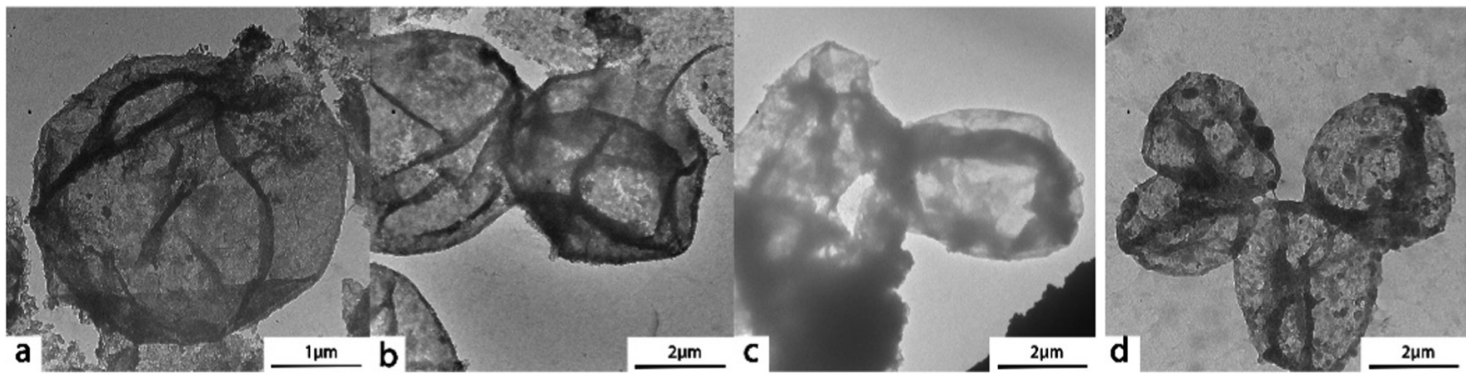

Fig. 1 TEM images of $(\mathrm{PAH} / \mathrm{GO})_{1} / \mathrm{PAH}(\mathrm{a}$ and $\mathrm{b}),(\mathrm{PAH} / \mathrm{GO})_{2} \mathrm{PAH}(\mathrm{c}),(\mathrm{PAH} / \mathrm{GO})_{3} \mathrm{PAH}(\mathrm{d})$.

Furthermore, the resultant secondary amine can react with ethylene oxide via a similar route, and the reaction is shown as follows: (PAH/GO) ${ }_{n} \mathrm{PAH}$-coated cotton fabrics were washed with $100 \mathrm{~mL}$ deionized water $\left(30^{\circ} \mathrm{C}, 10 \mathrm{~min}\right)$ for 5,10 , and 20 times to investigate the washing fastness of the coated fabrics. A piece of the coated fabric was fixed on the Al post using a conductive carbon tape, and $\mathrm{Au}$ and Pd were sputtered to make a conductive coating for SEM testing under an accelerating voltage of
$20 \mathrm{kV}$. The coating effect of microcapsules on cotton fabrics was measured via FTIR spectroscopy.

\section{Results and discussion}

\subsection{Morphology of $(\mathrm{PAH} / \mathrm{GO})_{n} \mathrm{PAH}$ microcapsules}

The size of $(\mathrm{PAH} / \mathrm{GO})_{n} \mathrm{PAH}$ microcapsules depends on the size of PSS-doped $\mathrm{CaCO}_{3}$ templates. The size distribution histograms
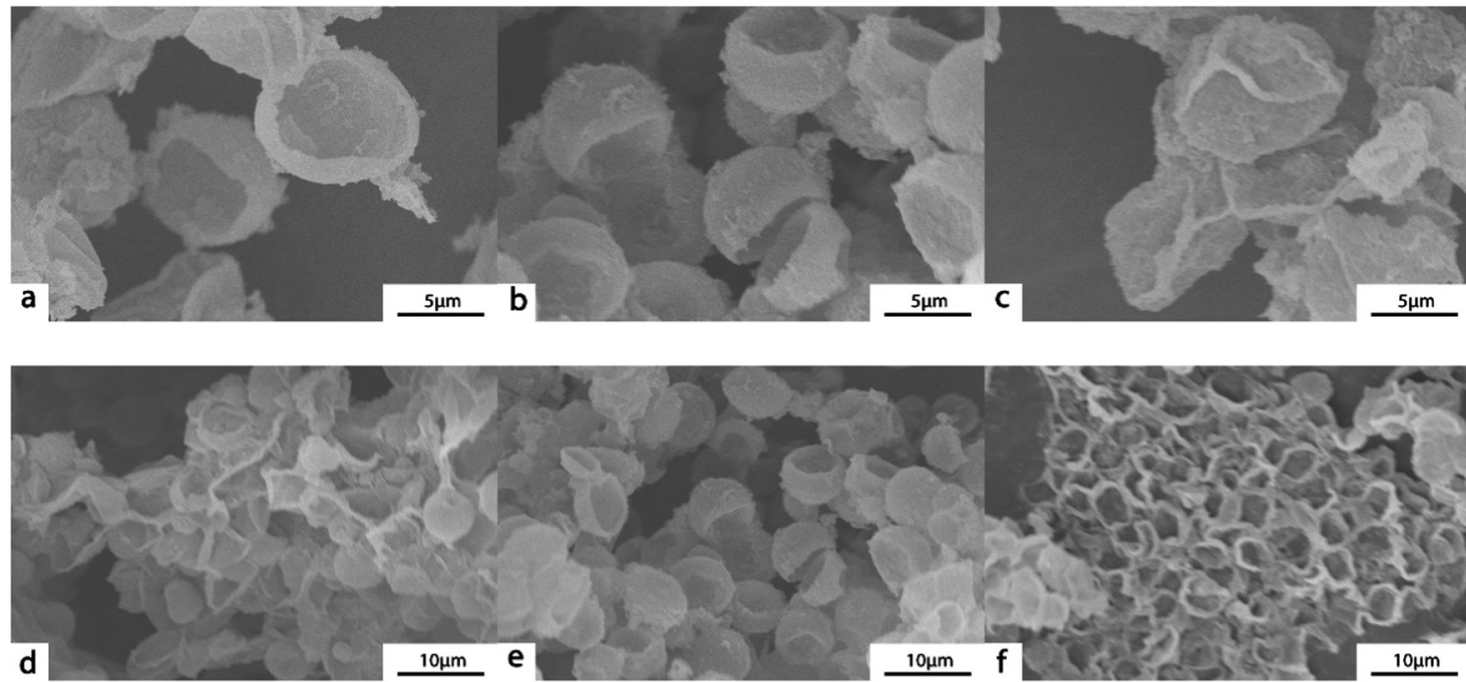

Fig. 2 SEM images of (PAH/GO) 1 /PAH ( $a$ and $d),(P A H / G O)_{2} P A H(b$ and $e),(P A H / G O)_{3} P A H$ (c and $\left.f\right)$.
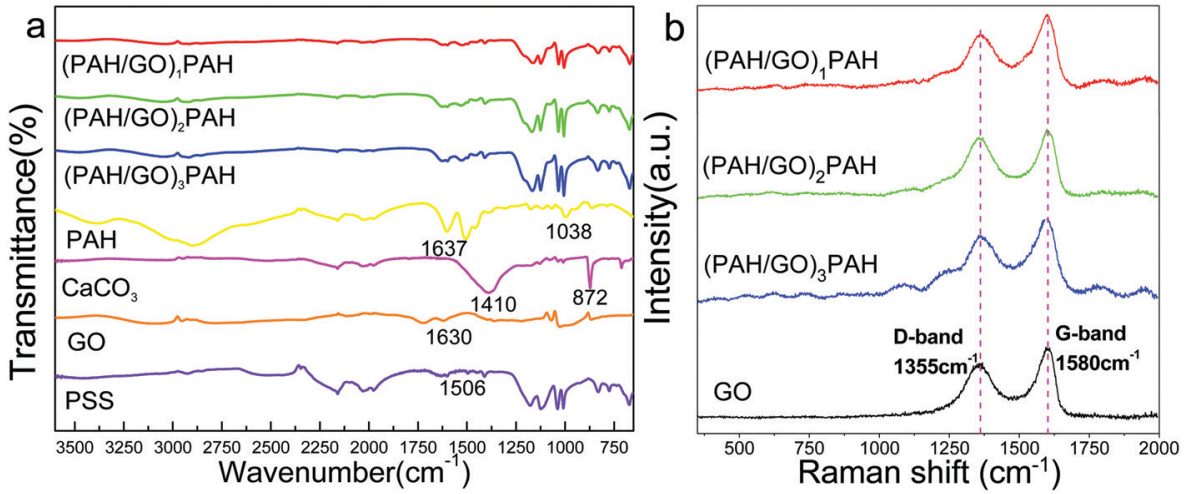

Fig. 3 FTIR spectra (a) and Raman spectra (b) of (PAH/GO) ${ }_{n} \mathrm{PAH}$ microcapsules. 

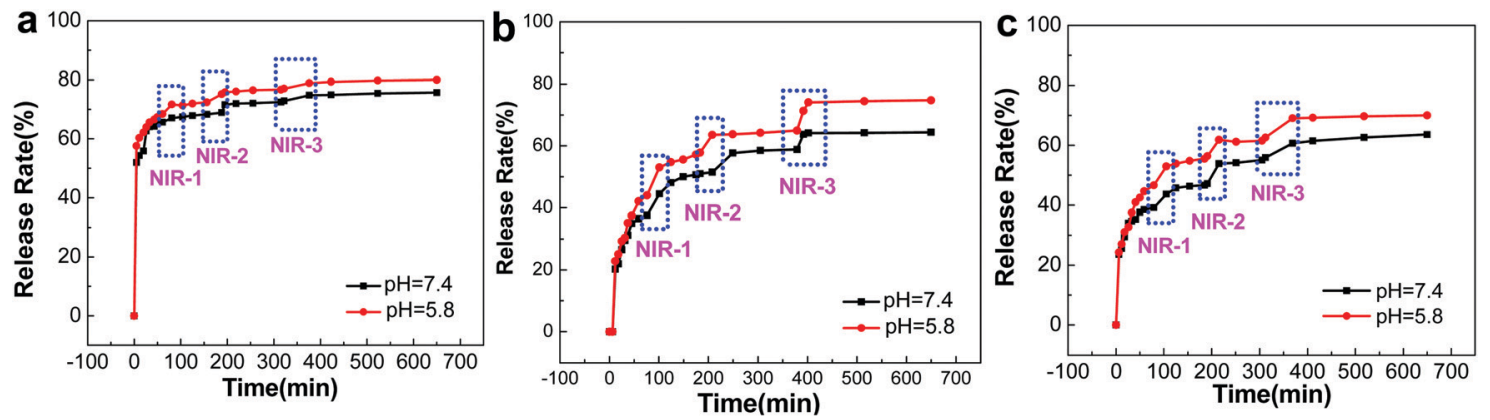

Fig. 4 NIR-triggered RhB release from (PAH/GO) $\mathrm{PAH}(\mathrm{a}),(\mathrm{PAH} / \mathrm{GO})_{2} \mathrm{PAH}$ (b) and (PAH/GO) ${ }_{3} \mathrm{PAH}(\mathrm{c})$ microcapsules. Each irradiation (blue zones) is with $808 \mathrm{~nm}$ NIR laser at $0.5 \mathrm{~W} \mathrm{~cm}^{-2}$ for $1 \mathrm{~min}$.

(Fig. S1, ESI $\dagger$ ) demonstrated that the diameter of the $\mathrm{CaCO}_{3}$ template ranged from $5 \mu \mathrm{m}$ to $7 \mu \mathrm{m}$. These monodispersed spherical PSS-doped $\mathrm{CaCO}_{3}$ particles with a negative charge were suitable as sacrificial templates for forming microcapsules via the LBL assembly. The morphology of (PAH/GO) ${ }_{n} \mathrm{PAH}$ has been shown in TEM images (Fig. 1). Microcapsules with different layers were prepared with the diameter of about $\sim 5 \mu \mathrm{m}$. The central $\mathrm{CaCO}_{3}$ templates were efficiently etched, generating a hollow structure as vectors for loading either drugs or dyes. Note that the SEM images confirmed the evidence of hollow structure through the visible collapse in the shell of the microcapsules during the drying process (Fig. 2). Furthermore, the diameter of microcapsules indicated by SEM images was $\sim 5 \mu \mathrm{m}$, in agreement with the TEM results.

\subsection{Structure of $(\mathrm{PAH} / \mathrm{GO})_{n} \mathrm{PAH}$ microcapsules}

The FTIR spectra of $(\mathrm{PAH} / \mathrm{GO})_{1} / \mathrm{PAH},(\mathrm{PAH} / \mathrm{GO})_{2} / \mathrm{PAH},(\mathrm{PAH} / \mathrm{GO})_{3} /$ $\mathrm{PAH}, \mathrm{PAH}, \mathrm{CaCO}_{3}$, GO and PSS are shown in Fig. 3a. The peaks located at $3540-3125 \mathrm{~cm}^{-1}$ were assigned to the $\mathrm{N}-\mathrm{H}$ group. Similarly, the peaks at $1690-1620 \mathrm{~cm}^{-1}$ were attributed to the stretching vibration of $\mathrm{C}=\mathrm{O}$; they suggested supramolecular interaction between the $-\mathrm{COO}^{-}$of $\mathrm{GO}$ and $-\mathrm{NH}_{3}{ }^{+}$of $\mathrm{PAH}$, leading to the formation of "salt-bridge". A strong absorption at $872 \mathrm{~cm}^{-1}$ corresponded to $\mathrm{CO}_{3}{ }^{2-}$, while the peak observed at $1410 \mathrm{~cm}^{-1}$ was attributed to the stretching vibration of $\mathrm{C}-\mathrm{O} .{ }^{34}$ The characteristic bands of PSS at $1038 \mathrm{~cm}^{-1}$ and $1123 \mathrm{~cm}^{-1}$ were attributed to the $\mathrm{S}-\mathrm{O}$ stretching vibration deformation and symmetric stretching of $\mathrm{S}=\mathrm{O}$ groups, respectively. ${ }^{35}$ The peaks at $2923 \mathrm{~cm}^{-1}$ were assigned to the asymmetric vibration of $\mathrm{CH}_{2}$ groups in $\mathrm{PAH}-\mathrm{Cl}$. The presence of protonated $-\mathrm{NH}_{3}{ }^{+}$groups in $\mathrm{PAH}-\mathrm{Cl}$ was confirmed by bands due to the asymmetric vibration of these species, which can be observed at $1612 \mathrm{~cm}^{-1} \cdot{ }^{36}$ The bands associated with oxygen-containing functional groups in GO at 1720, 1401 , and $1070 \mathrm{~cm}^{-1}$ were particularly assigned to the vibration of $\mathrm{C}=\mathrm{O}$ in carboxylic acid/or the carbonyl, $\mathrm{C}-\mathrm{O}-\mathrm{H}$ and $\mathrm{C}-\mathrm{O}$ groups. ${ }^{37}$ GO is hydrophilic because of the presence of polar oxygencontaining groups. The band observed at $1621 \mathrm{~cm}^{-1}$ was the stretching vibration of $\mathrm{C}=\mathrm{C}$. These peaks indicated efficient interaction between $\mathrm{PAH}$ and GO, generating a hollow structure of PAH/GO microcapsules. Furthermore, the Raman shift peaks are observed at $1355 \mathrm{~cm}^{-1}$ and $1594 \mathrm{~cm}^{-1}$, which represented the D-band and G-band of graphene, confirming the presence of GO in PAH/GO microcapsules (Fig. 3b). Here, the D-band was attributed to the structural disorder and defects induced on the $\mathrm{sp}^{2}$ hybridization, while the G-band represented the planar configuration of the $\mathrm{sp}^{2}$ bonded carbon that constitutes GO. ${ }^{38,39}$ The peaks at 1000$1100 \mathrm{~cm}^{-1}$ can be assigned to the $\mathrm{S}=\mathrm{O}$ stretching on PSS. ${ }^{40}$

\subsection{NIR-triggered RhB release from $(\mathrm{PAH} / \mathrm{GO})_{n} \mathrm{PAH}$ microcapsules}

A significant advantage of GO-based microcapsules is that due to the unique optical properties of GO, the release of chemicals
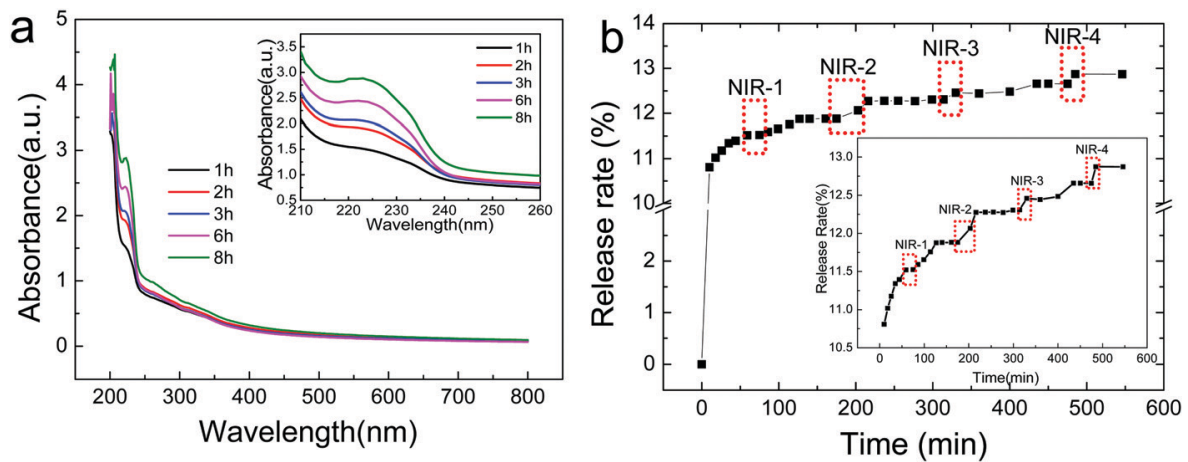

Fig. 5 Release of Atractylodes from (PAH/GO) ${ }_{2} \mathrm{PAH}$ microcapsules at $\mathrm{pH}=7.4$ buffer. (a) UV-visible spectra of Atractylodes releasing from microcapsules with an inlet of magnified image for peaks at $222 \mathrm{~nm}$. (b) NIR-triggered Atractylodes release from $(\mathrm{PAH} / \mathrm{GO}){ }_{2} \mathrm{PAH}$ microcapsules with a calibration inlet. Each irradiation (red zones) is with the $808 \mathrm{~nm} \mathrm{NIR} \mathrm{laser} \mathrm{at} 0.5 \mathrm{~W} \mathrm{~cm}^{-2}$ for $1 \mathrm{~min}$. 

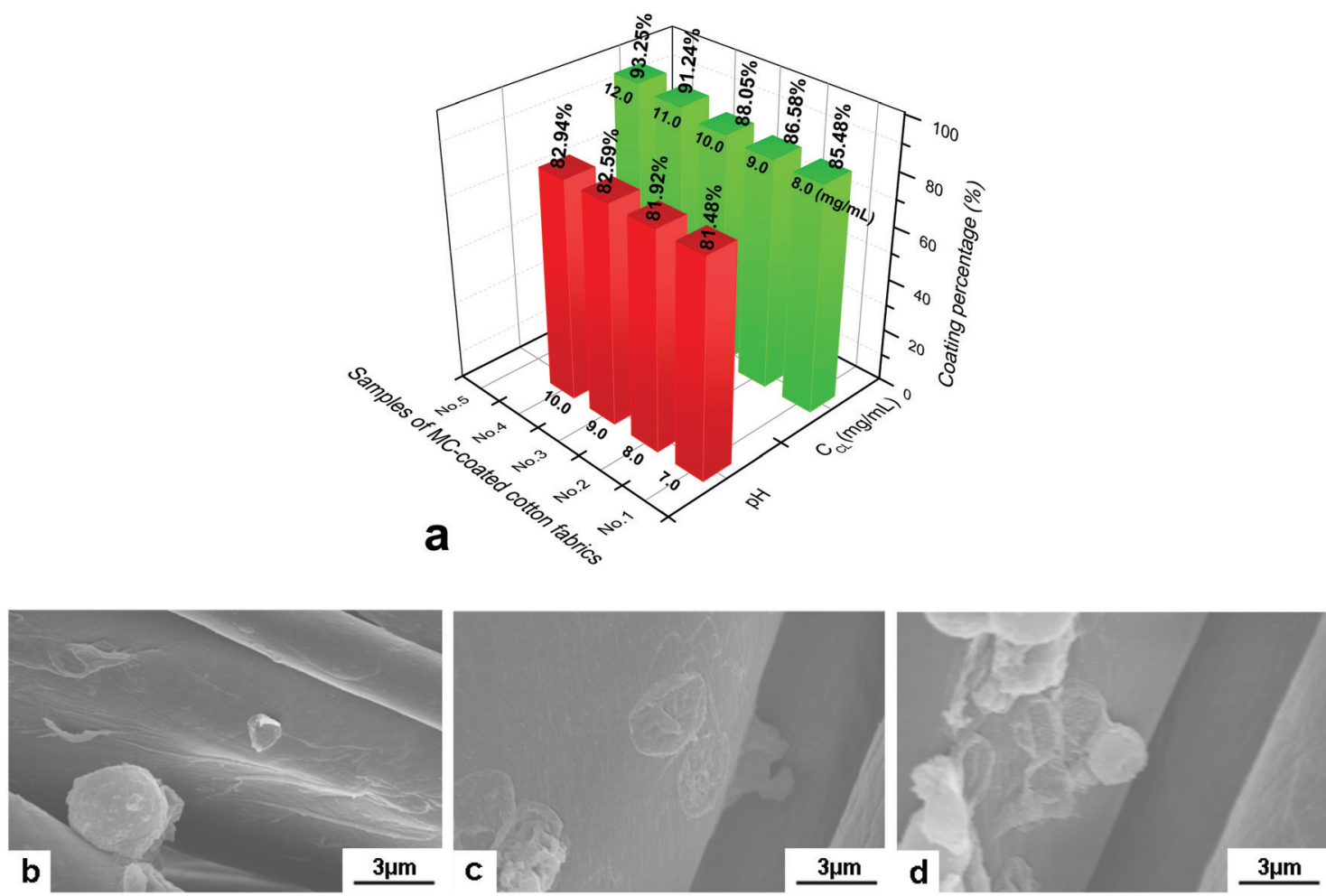

Fig. 6 Coating of $(\mathrm{PAH} / \mathrm{GO})_{2} \mathrm{PAH}$ microcapsules on cotton fibers. (a) Effect of $\mathrm{pH}$ and crosslinker (CL) on coating percentage; SEM images of the microcapsule-coated cotton fiber in different coating media, (b) $\mathrm{pH}=7.0$, (c) $\mathrm{pH}=10.0$ and (d) $\mathrm{CL}$ concentration of $12.0 \mathrm{mg} \mathrm{mL}^{-1}$ at pH $=7.0$. The initial number of microcapsules was $1.0 \times 10^{8}$.

can be remotely controlled by external stimulation, e.g. NIR radiation. ${ }^{41,42}$ Rhodamine $\mathrm{B}(\mathrm{RhB})$ was employed as a model molecule for investigating the permeability of $(\mathrm{PAH} / \mathrm{GO})_{n} \mathrm{PAH}$ microcapsules; the standard curve of Rhodamine $\mathrm{B}$ is shown in the ESI $\dagger$ (Fig. S2). RhB was mixed with $(\mathrm{PAH} / \mathrm{GO})_{n} \mathrm{PAH}$ microcapsules in PBS (pH 5.8) at room temperature for $24 \mathrm{~h}$. Then, microcapsules were washed by PBS (pH 7.4) to remove excess $\mathrm{RhB}$. The cumulative release of RhB from microcapsules with or without the NIR laser $\left(0.5 \mathrm{~W} \mathrm{~cm}^{-2}, 808 \mathrm{~nm}\right.$, irradiation for $1 \mathrm{~min}$ ) treatment was consequently tested via UV-vis spectroscopy for RhB-loaded microcapsules in solutions (pH 5.8 and 7.4). For microcapsules with three different layers, it was obvious that the release of all microcapsules at $\mathrm{pH} 5.8$ was higher than that at $\mathrm{pH}$ 7.4, confirming $\mathrm{pH}$-responsiveness of $\mathrm{PAH} / \mathrm{GO}$ microcapsules. The intermolecular interaction between $-\mathrm{COOH}$ (of $\mathrm{GO}$ ) and $-\mathrm{NH}_{2}$ (of $\mathrm{PAH}$ ) would be weakened in acidic solutions, and is beneficial for the permeable behavior. Interestingly, GO microcapsules showed a physically triggered release where NIR is considered to induce local heating through the photothermal conversion of GO, thus generating damage within the GO/PAH shell of microcapsules. ${ }^{43,44}$ Under the radiation of NIR laser, GO in the microcapsule layers heated its surroundings, leading to the relaxation of polyelectrolyte molecule chains and the disintegration of intermolecular interaction. This NIR irradiation contributed considerably to the accelerated release from GO microcapsules. The increase in release areas are highlighted in blue. And for microcapsules with different numbers of layers, this trend is similar (Fig. 4). For microcapsules $(\mathrm{PAH} / \mathrm{GO})_{n} \mathrm{PAH}$ with $n$ (layers) of 1,2 , and 3, the release percentage was $75.73 \%$, $65.02 \%$, and $63.56 \%$ at $\mathrm{pH} 7.4$ and $80.14 \%, 75.35 \%$, and $70.01 \%$ at $\mathrm{pH}$ 5.8. Note that the release rate decreases by increasing the layer number of microcapsules. The release rate is closely related to the thickness of the shell of microcapsules. Additional layers represent an extended route distance for diffusion. Moreover, there is additional blocking effect for releasing agents getting out of the microcapsules with additional layers. ${ }^{45,46}$
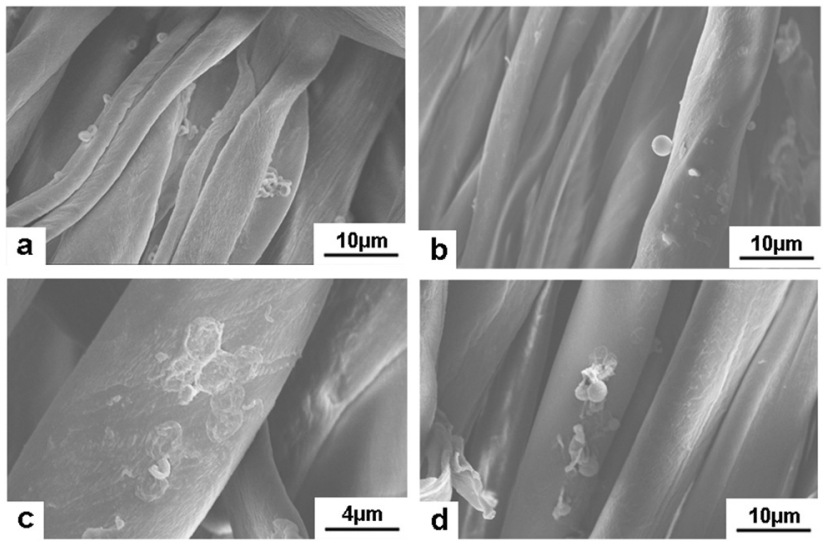

Fig. 7 SEM images of the microcapsule-coated cotton fibers after washing. ( $a$ and b) coating at $\mathrm{pH}=10.0$, washing 20 and 30 times; ( $c$ and d) coating at presence of $12.0 \mathrm{mg} \mathrm{mL}^{-1} \mathrm{CL}$, washing 20 and 30 times. The initial number of microcapsules was $1.0 \times 10^{8}$ 

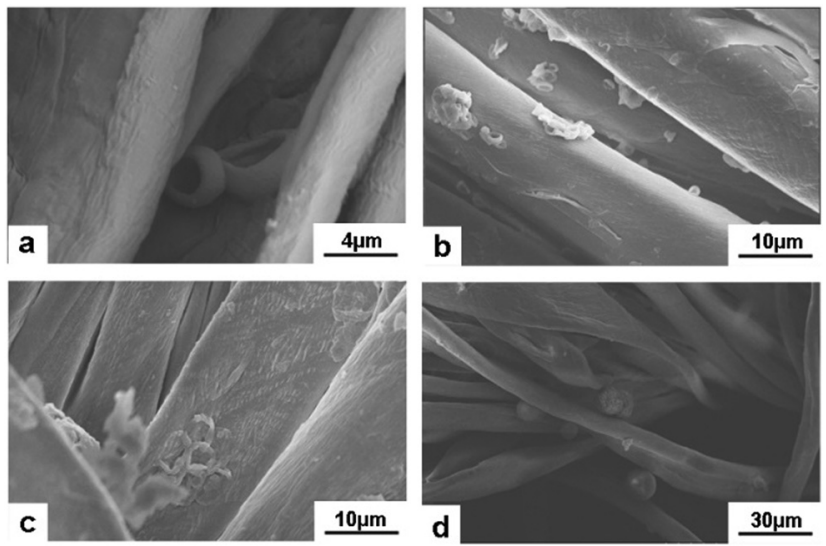

Fig. 8 Atractylodes-loaded microcapsules coated on cotton fibers at $\mathrm{pH}=7.0$ (a) and after washing 5 (b), 10 (c) and 20 (d) times.

\subsection{NIR-triggered Atractylodes release from $(\mathrm{PAH} / \mathrm{GO})_{n} \mathrm{PAH}$ microcapsules}

Atractylodes is a natural herb with complex components. Here, a UV spectrophotometer was used to monitor the releasing behavior of Atractylodes from (PAH/GO ${ }_{n} \mathrm{PAH}$ microcapsules, and the variation in Atractylodes releasing at different time intervals can be monitored by the maximum adsorption peak at $220 \mathrm{~nm}$ (Fig. 5a). The standard curve of the Atractylodes solution (Fig. S3, ESI $\dagger$ ) was determined by measuring the absorbance of the Atractylodes solution with different concentrations at $220 \mathrm{~nm}$. Then, the release of the Atractylodes solution in $(\mathrm{PAH} / \mathrm{GO})_{2} \mathrm{PAH}$ microcapsules with the intermittent treatment by the NIR laser $\left(0.5 \mathrm{~W} \mathrm{~cm}^{-2}, 808 \mathrm{~nm}\right.$, irradiating for $\left.1 \mathrm{~min}\right)$ was monitored. As shown in Fig. 4, because NIR has already been known to cause local heating in response to the GO photothermal conversion, the diffusion of Atractylodes out of (PAH/ $\mathrm{GO})_{2} \mathrm{PAH}$ microcapsules significantly accelerated (the red zones in Fig. 5b). During the entire release, it could be found that this enhancement of the release rate triggered by NIR in the plain stage (later period) was more obvious than that in the beginning period with a high permeability rate. This indicated that NIR was an efficient external stimulus promoting the availability of Atractylodes and demonstrating the potential application of Atractylodes-encapsulated textiles.

\subsection{Microcapsules for fabric coating}

Microcapsules were considered as good materials for textile modification. Certain functional ingredients can be loaded into the hollow space of microcapsules and then be connected with textile fibers through adsorption, electrostatic interaction and chemical bonding. Due to the carboxyl and hydroxyl groups on the surface, cellulose fiber was negatively charged, which can bond with the amino group of the outermost PAH layer of GO/PAH microcapsules with a positive charge. ( $\mathrm{PAH} / \mathrm{GO})_{2} \mathrm{PAH}$ was then used to study the microcapsule-coated cotton fibers. In alkaline conditions, $\mathrm{COOH}^{-}$ and $\mathrm{OH}^{-}$of cotton fiber was more ionized, improving the bonding with $-\mathrm{NH}_{3}{ }^{+}$of $(\mathrm{PAH} / \mathrm{GO})_{2} \mathrm{PAH}$. Moreover, in order to improve the interaction between $(\mathrm{PAH} / \mathrm{GO})_{2} \mathrm{PAH}$ and cotton fiber, an epoxyethane quaternary ammonium salt was used as the cross linker (CL) efficiently binding $(\mathrm{PAH} / \mathrm{GO})_{2} \mathrm{PAH}$ microcapsules with cotton fibers. The positively charged group $\mathrm{NR}_{4}{ }^{+}$of the cross-linker interacted with $-\mathrm{COO}^{-}(-\mathrm{COOH})$ or $-\mathrm{O}^{-}(-\mathrm{OH})$ groups of the cotton fiber, while the ethylene oxide groups bound with the $-\mathrm{NH}_{3}{ }^{+}$groups of the outermost layer PAH of the (PAH/GO $)_{2} \mathrm{PAH}$ microcapsules. As shown in Fig. 6, the bonding percentage of microcapsule with cotton fibers increased with the increase in $\mathrm{pH}$ or CL concentration. Without any CL, the number of coated microcapsules reached a maximum at $\mathrm{pH}$ 10. Moreover, compared with $\mathrm{pH}$, the enhancement in CL on connection between microcapsules and cotton fiber was much more remarkable, indicating strong interaction by chemical bonding. At a CL of $12.0 \mathrm{mg} \mathrm{mL}^{-1}$, the number of coated microcapsules was maximum. The morphology of cotton fiber modified with microcapsules was shown in the SEM image. The number of microcapsules connected with cotton fibers increased in the presence of alkaline media or CL. After washing 30 times, there were microcapsules on cotton fibers, which were more obvious when $12.0 \mathrm{mg} \mathrm{mL}{ }^{-1} \mathrm{CL}$ was used (Fig. 7). The number and percentage of microcapsules on the fabric are determined using hemocytometers.

Moreover, Atractylodes-loaded microcapsules were coated on cotton fibers. As shown in Fig. 8, $(\mathrm{PAH} / \mathrm{GO})_{2} \mathrm{PAH}$ was already coated on fibers. After washing by 5,10 , and 20 times, there were microcapsules coated on the textile. Fig. 9 showed the FTIR spectra of cotton fibers coated with Atractylodes-loaded microcapsules. The peaks at $1033 \mathrm{~cm}^{-1}$ and $670 \mathrm{~cm}^{-1}$ represented the $\mathrm{Ar}-\mathrm{H}$ in-plane vibration and $\mathrm{Ar}-\mathrm{H}$ out-of-plane bending, indicating
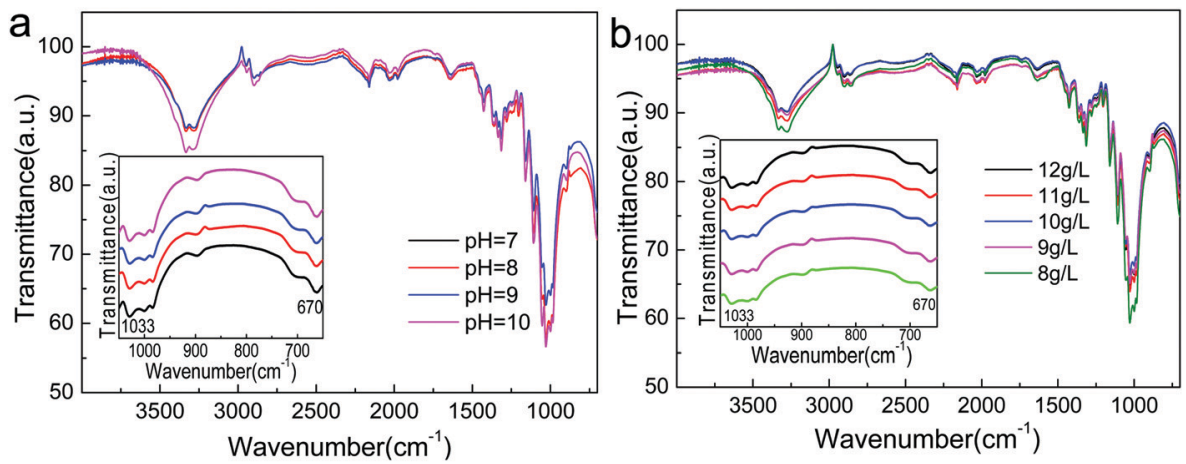

Fig. 9 FTIR spectra of Atractylodes-loaded microcapsules coated on cotton fibers at different pH (a) and CL concentrations (b). 
$(\mathrm{PAH} / \mathrm{GO})_{2} \mathrm{PAH}$ microcapsules were successfully connected with a cotton fiber. Moreover, the intensity of these peaks was enhanced with the increase in $\mathrm{pH}$ and $\mathrm{CL}$ concentration, confirming the results of SEM images.

\section{Conclusion}

In summary, $(\mathrm{PAH} / \mathrm{GO})_{n} \mathrm{PAH}$ microcapsules were prepared via an LBL self-assembly. The electrostatic interaction of oppositely charged PAH and GO nanosheets provided a robust shell with a hollow space centre to load drugs or dyes for controlled release through pH stimuli and NIR irradiation. NIR-triggered GO layer provided local heating and generated on-demand drug/dye release from $(\mathrm{PAH} / \mathrm{GO})_{n} \mathrm{PAH}$ microcapsules. Then, the hybrid $\mathrm{PAH} / \mathrm{GO}$ microcapsules can be coated on the cotton fabric to manufacture a medical care textile with both $\mathrm{pH}$ and NIR responsiveness. This study suggested a method to prepare stable GO composite microcapsules, which can be used as media to introduce chemicals to textiles, thus generating functional materials with controlled release behaviour under remote external stimulation. The microcapsule-coated textile can provide a new material beneficial to transdermal drug therapy and photothermal physiotherapy as well as a shield against the discomfort from the local overheating aroused by NIR irradiation. Moreover, the synergistic effect of photothermal treatment and herb care can lead to a potential healthcare textile with promising applications.

\section{Conflicts of interest}

There are no conflicts of interest to declare.

\section{Acknowledgements}

This work was supported by the National Key Research and Development Program of China (2017YFB0309800, 2016YFC0400503-02), the Natural Science Foundation of Tianjin, China (15JCYBJC18000, 18JCYBJC89600), the Xinjiang Autonomous Region Major Significant Project Foundation (2016A03006-3), and the Science and Technology Guidance Project of China National Textile and Apparel Council (2017011).

\section{References}

1 G. Liu, G. Lin, X. Lin, H. Zhou, H. Chen, L. Hao and X. Zhou, Environ. Sci. Pollut. Res., 2019, 26, 25107-25116.

2 J. Liu, Y. Lan, Z. Yu, C. S. Y. Tan, R. M. Parker, C. Abell and O. A. Scherman, Acc. Chem. Res., 2017, 50, 208-217.

3 C. Yang, H. Wu, X. Yang, J. Shi, X. Wang, S. Zhang and Z. Jiang, ACS Appl. Mater. Interfaces, 2015, 7, 9178-9184.

4 Y. Chen, W. Wei, Y. Zhu, J. Luo, R. Liu and X. Liu, ACS Appl. Mater. Interfaces, 2020, 12, 4821-4832.

5 Q. Yi and G. B. Sukhorukov, Adv. Colloid Interface Sci., 2014, 207, 280-289.
6 A. S. Timin, A. R. Muslimov, K. V. Lepik, N. N. Saprykina, V. S. Sergeev, B. V. Afanasyev, A. D. Vilesov and G. B. Sukhorukov, J. Mater. Chem. B, 2016, 4, 7270-7282.

7 W. C. Liao, S. Lilienthal, J. S. Kahn, M. Riutin, Y. S. Sohn, R. Nechushtai and I. Willner, Chem. Sci., 2017, 8, 3362-3373.

8 W. Zhang, L. Deng, G. Wang, X. Guo, Q. Li, J. Zhang and N. M. Khashab, Part. Part. Syst. Char., 2014, 31, 985-993.

9 A. Sharkawy, I. P. Fernandes, M. F. Barreiro, A. E. Rodrigues and T. Shoeib, Ind. Eng. Chem. Res., 2017, 56, 5516-5526.

10 X. Geng, W. Li, Y. Wang, J. Lu, J. Wang, N. Wang, J. Li and X. Zhang, Appl. Energy, 2018, 217, 281-294.

11 J. Huo, Z. Hu, G. He, X. Hong, Z. Yang, S. Luo, X. Ye, Y. Li, Y. Zhang, M. Zhang, H. Chen, T. Fan, Y. Zhang, B. Xiong, Z. Wang, Z. Zhu and D. Chen, Appl. Surf. Sci., 2017, 423, 951-956.

12 B. Brownell, Mater. Des., 2016, 90, 1238-1247.

13 X. Lin, S. Huang, K. Zhou and D. Zhang, Mater. Des., 2016, 107, 123-129.

14 X. Zhang, J. Tian, S. Gao, W. Shi, Z. Zhang, F. Cui, S. Zhang, S. Guo, X. Yang, H. Xie and D. Liu, J. Membr. Sci., 2017, 544, 368-377.

15 W. Huang, B. Liu, Z. Chen, H. Wang, L. Ren, J. Jiao, L. Zhuang, J. Luo and L. Jiang, Nanomaterials, 2017, 7, 277.

16 Y. Ma, Z. Li, H. Wang and H. Li, J. Colloid Interface Sci., 2019, 534, 469-479.

17 D. Sun, G. Sun, X. Zhu, A. Guarin, B. Li, Z. Dai and J. Ling, Adv. Colloid Interface Sci., 2018, 256, 65-93.

$18 \mathrm{~J} . \mathrm{Hu}, \mathrm{M}$. Chen, Z. Xiao and J. Zhang, J. Appl. Polym. Sci., 2014, 132, 41678.

19 F. S. Ghaheh, A. Khoddami, F. Alihosseini, S. Jing, A. Ribeiro, A. Cavaco-Paulo and C. Silva, Process Biochem., 2017, 59, 46-51.

20 D. Zhao, X. Jiao, M. Zhang, K. Ye, X. Shi, X. Lu, G. Qiu and K. J. Shea, $R S C$ Adv., 2016, 6, 80924-80933.

21 C. Ye, Z. A. Combs, R. Calabrese, H. Dai, D. L. Kaplan and V. V. Tsukruk, Small, 2014, 10, 5087-5097.

22 Y. Jin, J. Wang, H. Ke, S. Wang and Z. Dai, Biomaterials, 2013, 34, 4794-4802.

23 S. Hu, R. Fang, Y. Chen, B. Liao, I. Chen and S. Chen, Adv. Funct. Mater., 2014, 24, 4144-4155.

24 L. Deng, Q. Li, S. A. Al-Rehili, H. Omar, A. Almalik, A. Alshamsan, J. Zhang and N. M. Khashab, ACS Appl. Mater. Interfaces, 2016, 8, 6859-6868.

25 L. Shang, Y. Wang, Y. Yu, J. Wang, Z. Zhao, H. Xu and Y. Zhao, J. Mater. Chem. A, 2017, 5, 15026-15030.

26 Z. Zhang, M. Azizi, M. Lee, P. Davidowsky, P. Lawrence and A. Abbaspourrad, Lab Chip, 2019, 19, 3448-3460.

27 L. Manjakkal, S. Dervin and R. Dahiya, $R S C A d v .$, 2020, 10, 8594-8617.

28 E. Kilic, M. V. Novoselova, S. H. Lim, N. A. Pyataev, S. I. Pinyaev, O. A. Kulikov, O. A. Sindeeva, O. A. Mayorova, R. Murney, M. N. Antipina, B. Haigh, G. B. Sukhorukov and M. V. Kiryukhin, Sci. Rep., 2017, 7, 44159.

29 Y. Rui, B. Pang, J. Zhang, Y. Liu, H. Hu, Z. Liu, S. Ama Baidoo, C. Liu, Y. Zhao and S. Li, Artif. Cells, Nanomed., Biotechnol., 2018, 46, 15-24. 
30 M. Zhao, Q. Wang, Z. Ouyang, B. Han, W. Wang, Y. Wei, Y. Wu and B. Yang, Cytotechnology, 2014, 66, 201-208.

31 L. Chen, Y. Jan, P. Tsai, H. Norimoto, S. Michihara, C. Murayama and C. Wang, J. Agric. Food Chem., 2016, 64, 2254-2262.

32 N. Koonrungsesomboon, K. Na-Bangchang and J. Karbwang, Asian Pac. J. Trop. Med., 2014, 7, 421-428.

33 N. Sbirrazzuoli, A. Mititelu-Mija, L. Vincent and C. Alzina, Thermochim. Acta, 2006, 447, 167-177.

34 S. Ma, D. Wang, H. Zhong, Y. Gong, Y. Li and Q. Jiang, J. Mater. Sci., 2016, 51, 6836-6849.

35 L. A. Mercante, A. Pavinatto, L. E. O. Iwaki, V. P. Scagion, V. Zucolotto, O. N. Oliveira, L. H. C. Mattoso and D. S. Correa, ACS Appl. Mater. Interfaces, 2015, 7, 4784-4790.

36 F. J. Quites, C. Bisio, L. Marchese and H. O. Pastore, Mater. Res. Bull., 2013, 48, 3342-3350.

37 B. Ramezanzadeh, Z. Haeri and M. Ramezanzadeh, Chem. Eng. J., 2016, 303, 511-528.

38 J. Irigoyen, N. Politakos, E. Diamanti, E. Rojas, M. Marradi, R. Ledezma, L. Arizmendi, J. A. Rodríguez, R. F. Ziolo and S. E. Moya, Beilstein J. Nanotechnol., 2015, 6, 2310-2318.

39 M. W. Smith, I. Dallmeyer, T. J. Johnson, C. S. Brauer, J. McEwen, J. F. Espinal and M. Garcia-Perez, Carbon, 2016, 100, 678-692.

40 P. Singhal and S. Rattan, J. Phys. Chem. B, 2016, 120, 3403-3413.

41 L. L. Del Mercato, F. Guerra, G. Lazzari, C. Nobile, C. Bucci and R. Rinaldi, Nanoscale, 2016, 8, 7501-7512.

42 K. P. Loh, Q. Bao, G. Eda and M. Chhowalla, Nat. Chem., 2010, 2, 1015-1024.

43 R. K. Thapa, Y. S. Youn, J. Jeong, H. Choi, C. S. Yong and J. O. Kim, Colloids Surf., B, 2016, 143, 271-277.

44 P. Kalluru, R. Vankayala, C. Chiang and K. C. Hwang, Biomaterials, 2016, 95, 1-10.

45 M. Akbar, E. Cagli and I. Erel-Göktepe, Macromol. Chem. Phys., 2019, 220, 1800422.

46 W. Luo, L. Liu, G. Qi, F. Yang, X. Shi and X. Zhao, Appl. Environ. Microbiol., 2019, 85, e03128-18. 